\title{
Development of an Adherence Promotion Framework for Women with Diabetes in Pregnancy to Improve Adherence to Anti-Diabetic Therapy and Perinatal Outcomes
}

\author{
Doreen Macherera Mukona ${ }^{1 *}$, Stephen Peter Munjanja ${ }^{2}$, Mathilda Zvinavashe ${ }^{3}$ and Babill Stray-Pederson ${ }^{4}$ \\ ${ }^{1}$ University of Zimbabwe College of Health Sciences, Department of Nursing Science, Avondale, Harare, Zimbabwe \\ ${ }^{2}$ Obstetrician and Gynecologist, University of Zimbabwe College of Health Sciences, Department of Obstetrics and Gynecology, Avondale, Harare, Zimbabwe \\ ${ }^{3}$ University of Zimbabwe College of Health Sciences, Department of Nursing Science, Avondale, Harare, Zimbabwe \\ ${ }^{4}$ Specialist in Gynecology and Obstetrics- Institute of Clinical Medicine, Oslo University and Division Women and Children, Rikshospitalet, Oslo University Hospital, NO- \\ 0027 Oslo, Norway \\ "Corresponding author: Doreen Macherera Mukona, University of Zimbabwe College of Health Sciences, Department of Nursing Science, Avondale, Harare,
} Zimbabwe, Tel: +263773531031; E-mail: dmacherera@yahoo.co.uk

Received date: October 09, 2017; Accepted date: November 08, 2017; Published date: November 10, 2017

Copyright: $\odot 2017$ Mukona DM, et al. This is an open-access article distributed under the terms of the Creative Commons Attribution License, which permits unrestricted use, distribution, and reproduction in any medium, provided the original author and source are credited.

\begin{abstract}
Diabetes is now a major public health problem especially in developing countries. The purpose of this study was to develop an adherence promotion framework for diabetes in pregnancy. The study followed a mixed methods sequential dominant status design utilizing both quantitative and qualitative methods. Approval for the study was granted by the respective ethical review committees. All participants gave informed consent. The quantitative phase was conducted with a cohort of 157 pregnant women with a diagnosis of diabetes in pregnancy. The exposure was adherence to anti-diabetic therapy while the outcomes were perinatal outcomes. Data was collected using semi structured interviews and was analyzed using the Statistical Package for the Social Sciences (SPSS) version 20 and STATA. A descriptive qualitative design was used in the qualitative phase where four focus group discussions (FGDs) were held with pregnant women with diabetes. Eight key informant interviews (KII) were conducted with health professionals. Thematic analysis was separately done for the FGDs and KIls. Adherence to anti-diabetic therapy was suboptimal and the mean was $66.7 \%$. The most common adverse perinatal outcomes were $(34.4 \%)$, caesarean delivery $(45.9 \%)$ and macrosomia $(33.8 \%)$. There were significant associations between adherence and caesarean delivery ( $R R 1.90 \mathrm{Cl} 0.8$ to $2.03 \mathrm{p}>0.001$ ), low Apgar score (RR $1.95 \mathrm{Cl} 1.03$ to $3.69 \mathrm{p}>0.039$ ) and perinatal mortality (RR $3.08 \mathrm{Cl} 1.11$ to $8.52 \mathrm{p}>0.018$ ). Some barriers to adherence identified in the qualitative phase were financial barriers and lack of social support. Contextual factors deduced from the study were used to develop the Adherence Promotion Framework. Chinn and Kramer's theory of knowledge development was used to guide development of the Framework.
\end{abstract}

Keywords: Diabetes; Pregnancy; Adherence; Anti-diabetic therapy; Perinatal outcomes

\section{Introduction}

About 422 million adults were living with diabetes globally in 2014 [1]. The estimated prevalence of diabetes mellitus in the African region was $7.1 \%$ or 25 million adults above the age of 18 in 2014 [1]. Though only $5.2 \%$ (19.8 million) of people with diabetes are in sub-Saharan Africa (SSA), making it the region with the smallest diabetes population when compared to other regions SSA has the highest proportion of undiagnosed diabetes. Majority (62\%) of the African diabetes population aged 20-79 years is undiagnosed suggesting an underestimation of its prevalence [2].

In a recent systematic review the prevalence of diabetes in Zimbabwe was $5.7 \%$ [3]. The prevalence of pre-gestational diabetes mellitus (PGDM) type I and type II is included in the prevalence of diabetes mellitus and the prevalence and screening methods for type I and type II diabetes mellitus, are relatively well researched and understood in most countries [4]. The prevalence rate of GDM is unknown in many countries, but it generally reflects background prevalence of type II diabetes in the given population [5]. GDM is defined as diabetes diagnosed during pregnancy that is not clearly overt diabetes [6]. The prevalence of GDM, as reported in different studies, varies between $1 \%$ and $14 \%$ in all pregnancies depending on the genetic characteristics, environment of the population under study, screening and diagnostic methods employed and prevalence of type II diabetes mellitus $[7,8]$.

Adherence to anti-diabetic therapy in this study referred to adherence to diet, physical activity and medications. Diabetes affects pregnant women more than the non-pregnant population due to presence of more than usual pregnancy discomforts [9]. In PGDM, adhering to diet and maintaining appropriate blood sugar levels is a challenge in the presence of physiologic changes, including those that interfere with insulin use $[9,10]$. In GDM the need to learn about diabetes and management in a short space of time is a major challenge [9].

Various models of care have been developed for the care of diabetes. Some of the models include the Chronic Care Model, the Super Six Model and the New South Wales (NSW) Model of Care for People with Diabetes Mellitus and the International Diabetes Federation- GDM Model. However most of these models were developed for the developed countries and for diabetes in general, including non- 
Citation: Mukona DM, Munjanja SP, Zvinavashe M, Stray-Pederson B (2017) Development of an Adherence Promotion Framework for Women with Diabetes in Pregnancy to Improve Adherence to Anti-Diabetic Therapy and Perinatal Outcomes. J Diabetes Metab 8: 773 . doi: $10.4172 / 2155-6156.1000773$

Page 2 of 8

pregnant populations, and might not be appropriate for a developing country. There are fundamental differences that limit the appropriateness of these models such as lack of staff, lack of health care facilities and lack of finances. The IDF-GDM model was developed in India specifically for GDM. The Adherence Promotion Framework was developed in this study specifically for women with diabetes in pregnancy in Zimbabwe. Strict adherence to healthy lifestyle habits must be advocated in health policies worldwide to control diabetes mellitus, particularly in developing countries like Zimbabwe where access to and quality of health care are huge problems. The purpose of this study was to develop an adherence promotion framework for diabetes in pregnancy.

\section{Methods}

This was a mixed sequential dominant status design that was done in two phases. The quantitative phase utilized a cohort of 157 women with diabetes in pregnancy. The qualitative phase utilized a descriptive qualitative design where focus group discussions were held with women with diabetes in pregnancy and key informant interviews were conducted with health care workers directly involved in the care of women with diabetes in pregnancy. Approval for the study was granted by the appropriate ethical review boards. All participants gave informed consent. Participants in FGDs gave another separate consent.

\section{Quantitative phase}

Consecutive sampling was used to recruit respondents for the quantitative phase. Data on adherence to diet, physical activity and medications and perinatal outcomes were collected by use of interviewer administered questionnaires. Women were followed up from around the 20th week of gestation until six weeks after delivery to monitor perinatal outcomes. Data was analyzed using SPSS version 20 and STATA. Descriptive statistics were used to analyze data on adherence levels and perinatal outcomes. Generalized linear regression modeling was used to analyze the association between adherence and perinatal outcomes.

\section{Qualitative phase}

Four focus group discussions with women with diabetes in pregnancy were conducted to explore the barriers to and facilitators of adherence to anti-diabetic therapy. Number of FGDs was guided by saturation. Maximum variation sampling was used to select participants who would have exhibited the highest and the lowest levels of adherence to anti-diabetic therapy in the quantitative phase. Thematic analysis as recommended by Braun and Clarke [11] and Miles et al. [12] was used to analyze the data. The stages of thematic analysis followed were data organization, familiarization, transcription, coding, developing a thematic framework (searching for themes, reviewing, defining and naming them), indexing, displaying and reporting (interrelating and description of themes). Findings from the focus group discussions have already been published [13].

Eight key informant interviews with health care workers involved in the care of women with diabetes in pregnancy. Number of key informant interviews was guided by saturation. Interviews were thematically analyzed and findings were reported as themes and categories. Findings of the key informant interviews have already been published [14].

\section{Results}

This section presents an overview of results of the quantitative phase and findings of the qualitative phase.

\section{Quantitative phase}

Demographic data: Table 1 presents demographic variables. Forty (25.5\%) participants had Type I diabetes mellitus, 69 (43.9\%) had Type I while $48(30.6 \%)$ had GDM. Fifty (31.8\%) participants were aged between 30-34, 130 (82.8\%) were married 113 (72.0\%) had attained the ordinary level of education while 91 (58\%) were unemployed.

\begin{tabular}{|c|c|c|c|}
\hline Variable & Frequency & Percentage & Cumulative Percentage \\
\hline \multicolumn{4}{|c|}{ Type of Diabetes } \\
\hline Type I & 40 & 25.5 & 25.5 \\
\hline Type I1 & 69 & 43.9 & 69.4 \\
\hline GDM & 48 & 30.6 & 100 \\
\hline \multicolumn{4}{|l|}{ Age in Years } \\
\hline $18-24$ & 21 & 13.4 & 13.4 \\
\hline $25-29$ & 37 & 23.6 & 36.9 \\
\hline $30-34$ & 50 & 31.8 & 68.8 \\
\hline $35-39$ & 38 & 24.2 & 93 \\
\hline $40-44$ & 11 & 7 & 100 \\
\hline \multicolumn{4}{|l|}{ Marital Status } \\
\hline Single & 21 & 13.4 & 13.4 \\
\hline Married & 130 & 82.8 & 96.2 \\
\hline Cohabiting & 6 & 3.8 & 100 \\
\hline \multicolumn{4}{|c|}{ Level of Education } \\
\hline None & 1 & 0.6 & 0.6 \\
\hline Primary & 18 & 11.5 & 12.1 \\
\hline Ordinary & 113 & 72 & 84.1 \\
\hline Advanced & 10 & 6.4 & 90.4 \\
\hline Tertiary & 15 & 9.6 & 100 \\
\hline \multicolumn{4}{|c|}{ Employment Status } \\
\hline Unemployed & 91 & 58 & 58 \\
\hline Self employed & 39 & 24.8 & 82.8 \\
\hline Employed & 27 & 17.2 & 100 \\
\hline
\end{tabular}

Table 1: Demographic Variables (1) (N=157).

Table 2 presents adherence to anti-diabetic therapy ranges. Twentysix (16.6\%) scored below 50\%, 12 (7.6\%) scored from 50\%-59\%, 19 (12.1\%) scored from 60\%-69\%, 42 (26.8\%) scored from 70\%-79\%, 56 (35.6\%) scored from $80 \%-89 \%$ while 2 (1.3\%) scored from $90 \%$ and above. Fifty-eight (36.9\%) scored from $80 \%$ and above. 
Citation: Mukona DM, Munjanja SP, Zvinavashe M, Stray-Pederson B (2017) Development of an Adherence Promotion Framework for Women with Diabetes in Pregnancy to Improve Adherence to Anti-Diabetic Therapy and Perinatal Outcomes. J Diabetes Metab 8: 773 . doi: $10.4172 / 2155-6156.1000773$

Page 3 of 8

\begin{tabular}{|l|l|l|l|}
\hline Variable & Frequency & Percentage & Cumulative Percentage \\
\hline$<50$ & 26 & 16.6 & 16.6 \\
\hline $50-59$ & 12 & 7.6 & 24.2 \\
\hline $60-69$ & 19 & 12.1 & 36.3 \\
\hline $70-79$ & 42 & 26.8 & 63.1 \\
\hline $80-89$ & 56 & 35.6 & 98.7 \\
\hline $90-100$ & 2 & 1.3 & 100 \\
\hline
\end{tabular}

Table 2: Adherence to anti-diabetic therapy ranges $(\mathrm{N}=157)$.

\section{Adherence to anti-diabetic therapy}

Perinatal outcomes: Table 3 presents perinatal outcomes. Fifty-four (34.4\%) had hypertensive disorders while 72 (45.9\%) had caesarean delivery. Fifty-three (33.8\%) had macrosomia, 42 (26.8\%) had low Apgar score at 1 minute and 39 (24.8\%) had low Apgar score at 5 minutes.

\begin{tabular}{|l|l|l|}
\hline Variable & Frequency & Percentage \\
\hline PIH/Preeclampsia/Eclampsia & 54 & 34.4 \\
\hline Caesarean delivery & 72 & 45.9 \\
\hline Maternal DKA & 8 & 5.1 \\
\hline Maternal hypoglycemia & 25 & 15.9 \\
\hline Candidiasis/Vaginitis & 31 & 19.7 \\
\hline Preterm birth & 8 & 5.1 \\
\hline Perinatal mortality & 25 & 15.9 \\
\hline Low Apgar score at one minute & 42 & 26.8 \\
\hline Low Apgar score at 5 minutes & 39 & 24.8 \\
\hline Macrosomia & 53 & 33.8 \\
\hline Low birth weight & 11 & 7 \\
\hline Neonatal hypoglycemia & 24 & 15.3 \\
\hline
\end{tabular}

Table 4 presents associations between level of adherence and perinatal outcomes. There were significant associations with caesarean delivery, vaginitis/candidiasis, low Apgar score at 1 minute and at 5 minutes, perinatal mortality and neonatal.

\begin{tabular}{|c|c|c|c|}
\hline Variable & Risk ratio & $\begin{array}{l}\text { Confidence } \\
\text { interval }\end{array}$ & $P$ value \\
\hline \multicolumn{4}{|l|}{ Maternal Outcomes } \\
\hline Caesarean delivery & 1.9 & $0.8-2.03$ & $0.001^{*}$ \\
\hline Hypertension & 1.28 & $0.8-2.03$ & 0.305 \\
\hline Maternal DKA & 1.76 & $0.38-4.59$ & 0.473 \\
\hline Maternal hypoglycaemia & 1.5 & $0.68-3.34$ & 0.312 \\
\hline Preterm birth & 1.76 & $0.38-8.23$ & 0.473 \\
\hline Vaginitis/Candidiasis & 3.95 & $1.65-9.47$ & $0.002^{*}$ \\
\hline \multicolumn{4}{|l|}{ Neonatal Outcomes } \\
\hline Apgar $<7$ at 1 minute & 2.15 & $1.16-3.98$ & $0.015^{*}$ \\
\hline Apgar $<7$ at 5 minutes & 1.95 & $1.03-3.69$ & $0.039^{*}$ \\
\hline Macrosomia & 0.89 & $0.57-1.4$ & 0.619 \\
\hline Neonatal hypoglycaemia & 0.41 & $0.19-0.86$ & $0.019^{*}$ \\
\hline Perinatal Mortality & 3.08 & $1.11-8.52$ & $0.018^{*}$ \\
\hline
\end{tabular}

Table 4: Associations between level of adherence and perinatal outcomes $(\mathrm{N}=157)$.

\section{Qualitative phase}

This section presents findings of the qualitative phase.

Findings of focus group discussions: Table 5 presents themes and categories from focus group discussions

Findings of key informant interviews: Table 6 presents themes and categories from key informant interviews.

Table 3: Perinatal Outcomes (N=157).

\section{Barriers to adherence}

Category- Poor socio economic status

Lack of money to buy insulin and glucose testing strips

Poor storage facilities for insulin at home

Lack of storage facilities when travelling

Inability to pay for the numerous tests required

Lack of money to buy the required foods

Lack of money to hire personal trainers for specific exercises in pregnancy and to

buy indoor gadgets for exercise

Category- Inadequate social support

Lack of family support

Lack of peer support

Lack of community support

Category- Complicated treatment regimen

Painful to self-inject insulin

Art of injection process

\section{Facilitators of adherence}

Category - Getting family, peer and community support

Getting treatment buddies to foster adherence

Involvement of husbands in pre-conceptual and antenatal care

Pre-conceptual care and counseling of husbands

Support groups for women with diabetes

Establishment of gyms for pregnant women

Continuous health education to individuals, families and communities

Category - Getting financial support/Provision of free drugs and services

Availability of free drugs

Availability of glucometers and glucose testing strips

Having investigations done for free

Establishment of diabetic food programs

Active involvement of the Zimbabwe Diabetic Association

Category - Improvement of service at the hospitals

Establishment of specialized care units for women with diabetes in pregnancy 
Citation: Mukona DM, Munjanja SP, Zvinavashe M, Stray-Pederson B (2017) Development of an Adherence Promotion Framework for Women with Diabetes in Pregnancy to Improve Adherence to Anti-Diabetic Therapy and Perinatal Outcomes. J Diabetes Metab 8: 773 . doi: $10.4172 / 2155-6156.1000773$

Page 4 of 8

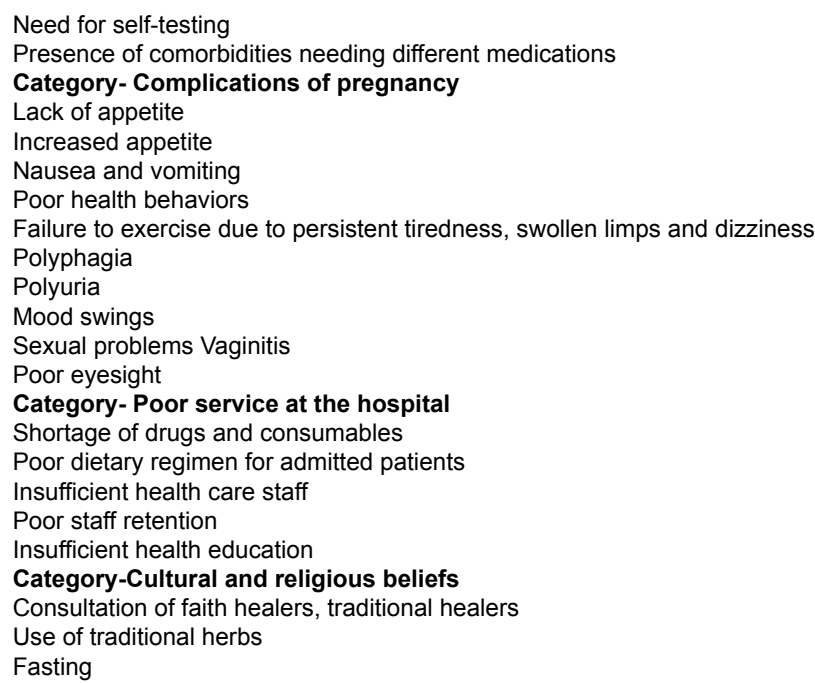

Table 5: Themes and categories from focus group discussions.

\begin{tabular}{|l|l|}
\hline $\begin{array}{l}\text { Barriers to adherence to anti- } \\
\text { diabetic therapy }\end{array}$ & $\begin{array}{l}\text { Facilitators of adherence to anti-diabetic } \\
\text { therapy }\end{array}$ \\
\hline $\begin{array}{l}\text { Financial barriers } \\
\text { Lack of health education on } \\
\text { diabetes in pregnancy } \\
\begin{array}{l}\text { Lack of trained personnel } \\
\text { Lack of collaboration among } \\
\text { health care workers } \\
\text { Shortage of staff }\end{array}\end{array}$ & $\begin{array}{l}\text { Subsidization of care } \\
\text { Strengthening health education } \\
\text { Formal training of health care workers in } \\
\text { management of diabetes in pregnancy } \\
\text { Collaboration among health care workers }\end{array}$ \\
\hline
\end{tabular}

Table 6: Themes and categories from key informant interviews.

\section{Discussion}

Findings of both phases of the study were integrated and used to develop the adherence promotion framework for women with diabetes in pregnancy to promote adherence and improve perinatal outcomes. It is hoped that the framework will be integrated into care of women with diabetes in pregnancy to strengthen the component of adherence to therapy. A framework is a broad overview, outline, or skeleton of interlinked items which supports a particular approach to a specific objective, and serves as a guide that can be modified as required by adding or deleting items [15]. It is a grouping of related concepts and theories that are of importance to nurses to guide practice, education and research in nursing [16]. A theory refers to the creative and rigorous structuring of ideas that displays a tentative, purposeful and systematic review of phenomena [17]. The adherence promotion framework will be discussed in terms of its purpose, underlying assumptions, definition of concepts of the framework and relationships and structure of the framework.

\section{Purpose of the framework}

The purpose of the framework is to promote patient adherence to anti-diabetic therapy in pregnancy to improve perinatal outcomes.
Regular comprehensive check-up, follow up and home visits

Decentralization of care to primary care centers

Involvement of other specialists besides doctors and nurses

Offering pre-conceptual care

Category - desire to have a live and healthy baby without adverse perinatal outcomes

The desire to have a well-baby

\section{Assumptions underlying the framework}

Assumptions of the Adherence Promotion framework are based on individuality, patient active participation, and high level of information flow, collaboration and organization of health care. Effective patientdriven health care should have a high level of information flow, transparency, customization, collaboration and patient choice and responsibility-taking [18].

Individuality: Individuality is the particular character, or aggregate of qualities, that distinguishes one person or thing from others; sole and personal nature. Individuality supports individual's own decision making. Care and support rendered should be tailored to individual needs and this upholds respect by preserving the individual's dignity, individuality and personal beliefs [19]. The care and support rendered to women with diabetes should be appropriate to their culture, socioeconomic status, age as well as personal preferences in order to promote their adherence to anti-diabetic therapy.

Patient active participation: Patient participation refers to involvement of the patient in decision making regarding treatment options, information sharing, and expression of feelings regarding health care instructions [20]. Enhanced patient participation, considers patients as equal partners in healthcare decision making [21]. Pregnant women with diabetes should actively participate in decision making regarding their own care. There is need for mutual goal setting with the health care provider. This ensures that the goals set are realistic for the patient and this will consequently promote adherence to anti-diabetic therapy.

High level of information flow: Information sharing is very crucial in health care. Health care workers should always keep women with diabetes in pregnancy informed about their own health, the health of the unborn baby, treatment options and any current information that may arise. On the other hand, patients must also keep the health care workers informed about experiences with diabetes in pregnancy and any challenges in adhering to therapy. This enables appropriate decision making in care and early intervention for any problems identified. 
Citation: Mukona DM, Munjanja SP, Zvinavashe M, Stray-Pederson B (2017) Development of an Adherence Promotion Framework for Women with Diabetes in Pregnancy to Improve Adherence to Anti-Diabetic Therapy and Perinatal Outcomes. J Diabetes Metab 8: 773 . doi: $10.4172 / 2155-6156.1000773$

Page 5 of 8

Collaboration and organization of health care: Strong collaboration between specialists and other members of the multidisciplinary team is important as patients circulate between different services and various specialists. Lack of collaboration negatively impact efficient management of diabetes in pregnancy [22,23]. Pregnant women with diabetes are managed by physicians, midwives, obstetricians and gynecologists, diabetologists, nutritionists, physiotherapists, counselors and community health nurses among other professionals. There is need for strong collaboration and organization of different levels of care in order to optimize care for patients.

\section{Definition of concepts of the framework}

Concepts are the ideas forming a theory that are expressed through language. The systematic integration of concepts enables their meanings to be conveyed by definitions. Conceptual definitions are decided by the theorist and they give the theory its particular character [17]. The concepts of the adherence promotion model as a proposed solution to non-adherence to anti-diabetic therapy are individual characteristics, influencers of adherence to anti-diabetic therapy, interventions that promote adherence, level of adherence to antidiabetic therapy and outcomes of adherence to anti-diabetic therapy. Table 7 presents concepts and sub-components of the framework (Figure 1).

\begin{tabular}{|c|c|}
\hline Concepts & Sub-components of concepts \\
\hline Individual Characteristics & Age, Type of diabetes, Gravidity, Parity, Family history of diabetes, Religion, Socioeconomic status, Support systems \\
\hline Influencers of Adherence & $\begin{array}{l}\text { Barriers to Adherence (Financial barriers, lack of knowledge, Poor health care system, psychological factors, pathophysiology of } \\
\text { diabetes, problems of pregnancy, Cultural and religious factors, lack of family and community support) } \\
\text { Facilitators of Adherence (Financial support, reorganization of health care, health education, social support, training of health care } \\
\text { workers) }\end{array}$ \\
\hline $\begin{array}{l}\text { Interventions to promote } \\
\text { adherence }\end{array}$ & $\begin{array}{l}\text { Health Education (Appropriate diet, exercise, management of symptoms of pregnancy and diabetes, self-injections, signs of } \\
\text { hypoglycemia and hyperglycemia, stress management) } \\
\text { Giving family and community support(Health education of families and communities, training of peer educators, use of community } \\
\text { resources) } \\
\text { Reorganization of health care (Improved Collaboration, Decentralization of some services to primary Care, Establishment of } \\
\text { diabetes in pregnancy Units, management of complications of pregnancy, management of complications of diabetes, adoption of } \\
\text { cheaper alternatives such as metformin for GDM) } \\
\text { Financial support (Glucometers, glucose testing strips, investigations, insulin) } \\
\text { Training of health Care workers }\end{array}$ \\
\hline Outcome of Interventions & Level of adherence to anti-diabetic therapy and maternal and neonatal outcomes of diabetic pregnancy \\
\hline
\end{tabular}

Table 7: Concepts and sub-components of the Adherence Promotion Framework.

\section{Relationships and structure of the framework}

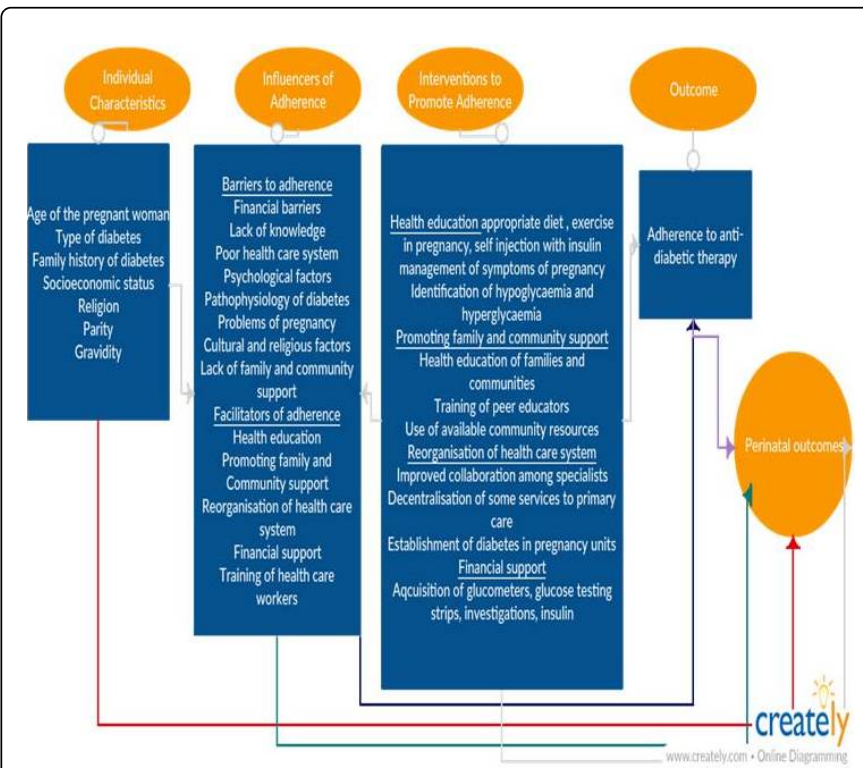

Figure 1: Adherence promotion framework.

\section{The Adherence Promotion Framework}

\section{Individual characteristics:}

Individual characteristics in the adherence promotion framework are the unique identifying characteristics of an individual. These are age, parity, type of diabetes gravidity, family history religion and socio economic status. Individual characteristics such as poor socioeconomic status can influence adherence to anti-diabetic therapy. If someone does not have the finances to buy required medications and consumables, she might end up not adhering to therapy. Individual characteristics can also directly influence perinatal outcomes. For example, adolescent motherhood is associated with adverse perinatal outcomes. Advancing age in pregnancy is also associated with adverse perinatal outcomes such as hypertensive disorders.

1. Influencers of adherence:

Influencers of adherence are either barriers to adherence or facilitators of adherence. Influencers of adherence can also be affected by individual characteristics.

\section{Barriers}

These are attributes that reduce adherence to therapy. These barriers were deduced from results of the quantitative phase and findings of the qualitative phase of the study. 
Citation: Mukona DM, Munjanja SP, Zvinavashe M, Stray-Pederson B (2017) Development of an Adherence Promotion Framework for Women with Diabetes in Pregnancy to Improve Adherence to Anti-Diabetic Therapy and Perinatal Outcomes. J Diabetes Metab 8: 773 . doi: $10.4172 / 2155-6156.1000773$

Page 6 of 8

Financial barriers: These refer to lack of finances. Participants in FGDs and key informant interviews cited lack of finances as a barrier to adherence to therapy. They cited lack of finances to access services, buy medications, glucose testing strips and required foods by patients. Majority participants (58\%) as revealed in the quantitative phase of the study were not employed and more than $80 \%$ earned below the poverty datum line. There are also financial barriers in the health care system leading to lack of consumables, required tests during pregnancy and poor remuneration of staff leading to high staff turnover and substandard services.

Lack of knowledge: This refers to lack of knowledge by participants on various aspects of adherence to anti-diabetic therapy in pregnancy. Participants reported lack of knowledge of proper affordable foods to eat and exercises to engage in in pregnancy among other aspects of diabetes care. This was also echoed in key informant interviews where participants also cited misconceptions in pregnancy such as eating for two that reduce adherence. Patients also reported lack of knowledge about acceptable blood glucose level, signs of hypoglycemia or hyperglycemia and what to do if they occur and this in turn caused them to skip insulin doses.

Poor health care system: Some factors contributing to poor health care system identified were high staff turnover, lack of trained staff, congestion in the ANC and inadequate time for consultation with health care professionals. Participants also reported lack of consumables in hospitals such as glucometers and glucose testing strips. Participants in key informant interviews mentioned lack of laboratories and other key health care workers such as endocrinologists, nutritionists and physiotherapists.

Psychological factors: These are feelings of fear and anxiety associated with having a pregnancy affected by diabetes. This compromises adherence to therapy. It has been reported in literature that fears and anxiety do reduce adherence to therapy.

Diabetes related factors: Classic symptoms of diabetes such as polyphagia, polyuria and polydipsia negatively influence adherence. They tend to compromise the recommended number of meals per day and patients might end up eating excessively. Patients might not engage in exercise, as reported in focus group discussions, for fear of getting hurt and not heal in time. Retinopathy associated with diabetes compromises adherence to exercise as patients fear exercising when they cannot see properly. In this study $43.3 \%$ participants reported vision problems. Some patients draw wrong doses of insulin because they cannot see well.

Problems of pregnancy: Nausea and vomiting common in pregnancy reduce adherence to diet. Some women have cravings for certain foods that might not be recommended in diabetes. Tiredness, dizziness, leg cramps and swelling of lower limbs reduce adherence to exercise during pregnancy. In the quantitative phase of the study, majority participants reported tiredness (72.6\%), nausea and vomiting (53.5\%) and headache (51\%). The growing abdomen might also hinder effective exercise during pregnancy.

Cultural and religious factors: Cultural factors such as use of herbs and consultation of traditional leaders are a barrier to adherence to medications. Some religious practices such as fasting for healing also reduce adherence to diet as pregnant women are required to eat 5-6 frequent meals to maintain normal blood glucose. Majority participants (87.3\%) were Christians and these might engage in practices such as fasting. A further $7 \%$ belonged to the Apostolic faith religion that also believes in faith healing and might shun advice given by health care workers.

Lack of family, peer and community support: Lack of support reduces adherence to therapy. Most pregnant women depend on their husbands for upkeep. It was reported in literature that some families might not prioritise the health of a diabetic pregnant woman or might not appreciate the need for stricter glycemic control during pregnancy. It was also reported in focus group discussions that some communities did not understand the need for such aspects as exercise in diabetes in pregnancy and pregnant women were perceived as showing off when they came out to jog on the streets.

\section{Facilitators}

These are the attributes that promote adherence.

Financial support: There is need for subsidization of costs of care and free availability of essential consumables such as glucose testing strips. This would address challenges of lack of insulin and consumables both in hospital and at home. Food programs such as the ones available for people living with HIV and AIDS to enhance adherence to diet were also suggested.

Reorganization of health care: Decentralization of services to primary care was suggested. Setting up a unit dedicated to the care of women with diabetes in pregnancy that will enable comprehensive management including management of complications of diabetes in general was suggested. Collaboration among health care workers should be strengthened. Cheaper alternatives such as use of oral hypoglycemic agents for GDM and type II diabetes can be used to ease the financial burden exerted by use of insulin. Community based peer educators can be trained to improve health education on diabetes in pregnancy. There can be in-service training of staff on diabetes in pregnancy or introduction of formal training courses. Physiotherapists must be involved in the care of pregnant women with diabetes to give education on physical activity.

Health education: There is need for health education on diet and appropriate and effective exercises during pregnancy that can be done without necessarily signing up with a gym. Health education on signs and symptoms of complications is also important. There is need for health education on diabetes in pregnancy to the general population to increase understanding and promote social support to women with diabetes in pregnancy.

Social support: Social support is very important in promoting adherence to therapy. This is in view of the fact that most pregnant women are not employed and will depend on their spouses or families for support. Community support is also essential to promote adherence.

\section{Interventions to promote adherence}

Interventions were informed by influencers of adherence. They are closely linked to the facilitators of adherence. Interventions also improve perinatal outcomes.

Health education: Participants mentioned importance of health education on appropriate and affordable diet, exercises to engage in in pregnancy, management of symptoms of pregnancy and diabetes, selfinjections, signs of hypoglycemia and hyperglycemia and stress management. Demonstrations on insulin injections and return demonstrations should be done with patients to ensure understanding and mastery of the correct injection technique. Nationwide campaigns 
Citation: Mukona DM, Munjanja SP, Zvinavashe M, Stray-Pederson B (2017) Development of an Adherence Promotion Framework for Women with Diabetes in Pregnancy to Improve Adherence to Anti-Diabetic Therapy and Perinatal Outcomes. J Diabetes Metab 8: 773 . doi: $10.4172 / 2155-6156.1000773$

Page 7 of 8

can be done to sensitize the nation at large about diabetes in pregnancy, pamphlets in both English and vernacular languages must be developed and given out freely to patients and the population at large. The social media which is very fast in transmitting messages must be used as a platform for dissemination of information.

Giving family and community support: Support from families and community was identified as a facilitator of adherence to anti-diabetic therapy. Health education of families and communities was recommended in focus group discussions. Majority participants (58\%) were unemployed and probably depended on spouses and family for financial support. Health education of the key resource persons is important to gain their understanding of diabetes in pregnancy as well as its financial, psychological and social demands. Training of community based peer educators was also recommended as a facilitator of adherence as these would be more accessible to women with diabetes in pregnancy in their communities. Home visits should be done for diabetic pregnant women to fully understand their home environments and give appropriate health education. Support groups should be utilized for women with diabetes in pregnancy.

Reorganization of health care: Improved collaboration of health care workers in the community and at central hospitals was recommended in key informant interviews. This ensures continuity of comprehensive care to diabetic pregnant patients. Decentralization of some services to primary care will improve access to services as women are seen at primary care centres based in their communities. This will reduce transport costs and waiting times at central hospitals. Decentralization will also need to be complemented by training of health care workers that will care for patients at primary care centres. Training of health care workers will equip them with the necessary health education and current knowledge of management of diabetes in pregnancy. This ensures that pregnant women follow correct and beneficial instructions. Establishment of a unit dedicated to management of diabetes in pregnancy will improve collaboration among care givers thus ensuring comprehensive care of patients. Caregivers will comprise midwives, obstetricians and gynecologists, physicians, dieticians, physiotherapists, counselors, ophthalmologists, radiologists and other relevant caregivers.

Financial support: Financial support can be in the form of subsidization of cost of medications, glucometers, glucose testing strips and services. Essential services include laboratory services and other important tests such as $\mathrm{HbA1C}$ and ultra sound scans. Numerous ultra sound scans, for foetal monitoring are required during pregnancy. Financial support should also be directed to the health care system. This will ensure comprehensive care of admitted diabetic pregnant women and promote adherence to therapy.

\section{Outcome of interventions}

The major outcome of the adherence promotion framework is improved adherence to anti-diabetic therapy. This in turn will lead to reduced incidence of adverse perinatal outcomes. Perinatal outcomes are also affected by individual characteristics such as the type of diabetes and age. This underscores the importance of individualized health education to empower women with diabetes to take optimum self-care to improve adherence and perinatal outcomes.

\section{Conclusion}

The adherence promotion framework, guided by Chinn and Kramer framework for knowledge development, was developed as a solution to the problem of non-adherence to therapy in pregnancy. Though various models of care have been developed for the care of people with diabetes, most of them were developed in developing countries and might be difficult to implement in a resource limited setting. However the adherence promotion framework has been specifically developed for diabetes in pregnancy including pre-gestational types I and II diabetes in Zimbabwe. It is hoped that utilization of this model will improve adherence to anti-diabetic therapy and help to reduce incidence of adverse perinatal outcomes.

\section{Acknowledgements}

The study was funded by the NORHED Grant to the University of Zimbabwe College Of Health Sciences, Department of Nursing Science

\section{Conflict of Interest}

The authors of this manuscript declare no conflict of interest regarding publication of this manuscript.

\section{References}

1. World Health Organization (2016) Global report on diabetes. World Health Organization: Geneva.

2. International Diabetes Federation (2013) Diabetes Atlas (6thedn) International Diabetes Federation: Brussels.

3. Mutowo M, Gowda U, Mangwiro JC, Lorgelly P, Owen A, et al. (2015) Prevalence of diabetes in Zimbabwe: a systematic review with metaanalysis. Int J Public Health 60: 1-11.

4. Macaulay S, Dunger DB, Norris SA (2014) Gestational diabetes mellitus in Africa: a systematic review. PLoS One 9: 97871.

5. Hunt KJ, Schuller KL (2007) The increasing prevalence of diabetes in pregnancy. Obstet Gynecol Clin North Am 34: 173-199.

6. American Diabetes Association (2015) Classification and diagnosis of diabetes. Diabetes Care 38: S8-S16.

7. Jang HC (2011) Gestational diabetes in Korea: incidence and risk factors of diabetes in women with previous gestational diabetes. Diabetes Metab J 35: 1-7.

8. Keshavarz M, Cheung NW, Babaee GR, Moghadam HK, Ajami ME, et al. (2005) Gestational diabetes in Iran: incidence, risk factors and pregnancy outcomes. Diabetes Res Clin Pract 69: 279-286.

9. Brooten D, Youngblut JM, Hannan J, Guido-Sanz F, Neff DF, et al. (2012) Health problems and APN interventions in pregnant women with diabetes. Pac Rim Int J Nurs Res Thail 16: 85.

10. White KM, Terry DJ, Troup C, Rempel LA, Norman P (2010) Predicting the consumption of foods low in saturated fats among people diagnosed with Type 2 diabetes and cardiovascular disease. The role of planning in the theory of planned behaviour. Appetite 55: 348-354.

11. Braun V, Clarke V (2006) Using thematic analysis in psychology. Qualitative Res Psychol 3: 77-101.

12. Miles MB, Huberman AM, Saldana J (2014) Fundamentals of qualitative data analysis. Qualitative data analysis (3rdedn) CA: Sage Thousand oaks.

13. Mukona D, Munjanja SP, Zvinavashe M, Stray-Pederson B (2017) Barriers of Adherence and Possible Solutions to Nonadherence to Antidiabetic Therapy in Women with Diabetes in Pregnancy: Patients' Perspective. J Diabetes Res 2017: 3578075.

14. Mukona D, Munjanja S, Zvinavashe M, Stray-Pederson B (2017) Barriers and Facilitators of Adherence to Anti-Diabetic Therapy in Pregnant Women with Diabetes: Health Care Workers' Perspectives J Diabet Mellitus 7: 160-174.

15. Business Dictionary (2017) Framework.

16. Medical Dictionary for the Health Professions and Nursing (2017) Nursing Conceptual Framework. 
Citation: Mukona DM, Munjanja SP, Zvinavashe M, Stray-Pederson B (2017) Development of an Adherence Promotion Framework for Women with Diabetes in Pregnancy to Improve Adherence to Anti-Diabetic Therapy and Perinatal Outcomes. J Diabetes Metab 8: 773 . doi: $10.4172 / 2155-6156.1000773$

Page 8 of 8

17. Chinn P, Kramer M (2010) Integrated theory \& knowledge development in nursing. Elsevier Health Sciences.

18. Swan M (2009) Emerging patient-driven health care models: an examination of health social networks, consumer personalized medicine and quantified self-tracking. Int J Environ Res Public Health 6: 492-525.

19. Tutor H (2017) Values Of Person Centred Care.

20. Vahdat S, Hamzehgardeshi L, Hessam S, Hamzehgardeshi Z (2014) Patient involvement in health care decision making: a review. Iran Red Crescent Med J 16: 12454

21. Farrell C (2004) Patient and public involvement in health: the evidence for policy implementation: a summary of the results of the Health in Partnership research programme. Department of Health
22. Nielsen KK, de Courten M, Kapur A (2012) Health system and societal barriers for gestational diabetes mellitus (GDM) services-lessons from World Diabetes Foundation supported GDM projects. BMC Int Health Hum Rights 12: 33.

23. Utz B, Delamou A, Belaid L, De Brouwere V (2016) Detection and Management of Diabetes during Pregnancy in Low Resource Settings: Insights into Past and Present Clinical Practices. J Diabetes Res 2016: 3217098 . 